\title{
Reflection as a Learning Tool in Postgraduate Medical Education
}

\author{
Attia Bari, Izza Imran, Habib Ullah, Ali Arshad, Irfan Naeem and Nadia Sadaqat \\ Department of Paediatric Medicine, The Children's Hospital and ICH, Lahore, Pakistan
}

\begin{abstract}
Objective: To explore the reflective capacity as a learning tool in pediatric residents.

Study Design: Survey.

Place and Duration of Study: The Children's Hospital Lahore, Pakistan from $20^{\text {th }}$ March to $30^{\text {th }}$ March 2021.

Methodology: In this cross sectional online survey, the participants were postgraduate residents and registrars of Paediatric Medicine, Paediatric Surgery, and Paediatric Diagnostics, working at The Children's Hospital, Lahore, Pakistan. Reflective practices questionnaire (RPQ) was used for measuring the reflective practices and SPSS-24 for data analysis.

Results: Out of a total of 175 study participants, 144 (82.3\%) were paediatric medicine residents followed by paediatric surgery $18(10.3 \%)$ and paediatric diagnostic $13(7.4 \%)$ with a slight female preponderance $91(52 \%)$. All years of trainees participated; majority was $4^{\text {th }}$ year trainees $58(33.1 \%)$, and $1^{\text {st }}$ year the lowest $17(9.7 \%)$. The overall mean score of the questionnaire was $69.97 \pm 10.79$ (95\% Cl: $68.36 \pm 71.58)$ out of 96 total score. The highest score was of critical appraisal $18.52 \pm 3.16$ ( $95 \% \mathrm{Cl}: 18.04 \pm 18.99$ ) out of 24 . There was no difference in mean score of different sub-domains and mean scores based on gender, specialty or year of training $(p=>0.05)$.

Conclusion: The overall reflective capacity of paediatric postgraduate residents is good irrespective of specialty, gender or year of training. Critical appraisal of interaction in the reflection is the highest scored domain.
\end{abstract}

Key Words: Postgraduate, Residents, Medical education, Reflection, Practice, Learning tool.

How to cite this article: Bari A, Imran I, Ullah H, Arshad A, Naeem I, Sadaqat N. Reflection as a Learning Tool in Postgraduate Medical Education. J Coll Physicians Surg Pak 2021; 31(09):1094-1098.

\section{INTRODUCTION}

The educational journey of a clinician is perpetuated as a process of lifelong learning, necessary for improving patient care through upgrading one's knowledge and skills. An ongoing learning process of healthcare providers takes place by continuing medical education. ${ }^{1}$ A variety of checklists and tools were used in the past decade to document or evaluate reflection among the clinicians; and the portfolios is considered as one of those popular tools. ${ }^{2}$ While being commonly used in various contexts, from physics to education, the term 'reflection' remains true to its Latin origins, meaning 'to bend' or 'to turn around'.

When viewed in the educational background, reflection is considered as a process by which thoughts are 'turned back' in order to interpret or analyse them over and over again.

Correspondence to: Dr. Attia Bari, Department of Paediatric Medicine, The Children's Hospital and ICH, Lahore, Pakistan

E-mail:drattiabari@gmail.com

Received: March 20, 2021; Revised: May 14, 2021;

Accepted: May 24, 2021

DOI: https://doi.org/10.29271/jcpsp.2021.09.1094
Typically the trigger or the starting point for this process is an incident or a problem resulting in increased awareness of the situation. Whenever in future a similar incident happens, these observations will then be used to improve the outcome in that case. $^{3}$

During their clinical years, the students of medical sciences have to face events which often traumatise them emotionally; and these educational experiences, most of the times remains unaddressed. Students need support of educators or supervisors in cathartic release of their pent up emotions that arise from their clinical encounters. The process of reflection and reflective practices are helpful in lifelong learning and a higher level of career. ${ }^{4}$

In addition, reflection leads to 'transformative learning' and learners gain insights into their own perceptions and responsibilities in the delivery of healthcare. In general and especially within medical education, the acquisition of reflective ability in students has become a central element of many university courses in the health sciences. During the academic studies and clinical practices of the students, a tendency is developed amongst them to involve themselves in reflective beliefs. ${ }^{5}$

Along with the practice of self-reporting reflection initiative in medical learning, both healthcare practitioners and their students, including postgraduate residents, need to encourage 
reflective practices. The importance of qualified facilitators cannot be overstated. It is the teachers' duty to assist students in approaching learning tasks in a systematic manner. Through reflective practice, teachers or facilitators assist students in tracking their development, constructing meaning from learned material and applying their knowledge and skills to new contexts and environments. ${ }^{6}$

A regular and secure reflective supervision is the most common method of developing reflective ability in healthcare providers. There is scarcity or research on reflective capacity and practices in the postgraduate medical education. Therefore, this study was conducted to explore the reflective capacity of the postgraduate residents, working in the field of paediatrics, which is a very sensitive field.

\section{METHODOLOGY}

This cross sectional survey was conducted from $20^{\text {th }}$ March to $30^{\text {th }}$ March 2021 at the Children's Hospital and the Institute of Child Health Lahore ( $\mathrm{CHICH})$, which is the biggest postgraduate training institute and a tertiary care hospital for paediatrics. Ethical approval was obtained from Institution Review Board, CHICH (No.2021-254-CHICH, dated: 18.03-2021). Postgraduate residents of all four years of training, including registrars of paediatric medicine, paediatric surgery, and paediatric diagnostics working at the $\mathrm{CHICH}$, were included; because in all three specialties the residents have different types of interaction with the patients and different learning experiences. The sample size of 175 postgraduate residents was calculated with $95 \%$ confidence level and $5 \%$ margin of error by taking 320 postgraduate residents working in The Children's Hospital, Lahore. Paediatric medicine, being the major specialty of $\mathrm{CHICH}$, had maximum number of residents.

For measuring the reflective practices, reflective practices questionnaire (RPQ) was used, which is a reliable measure for reflective capacity (Cronbach's alpha value $=0.84$ ) created by Priddis and Rogers, as it assess a wider range of psychological areas, relevant to reflective practice. 5 The four-item sub-components in this 16-itemed RPQ scale, included reflection-in-action (reflection happening during the moment of clinical encounter; reflection-on-action (reflection on past events/clinical encounter); reflection with others (reflection with colleagues/peers); and self-appraisal (an increased tendency to question and reflect upon one's own capabilities for practice in clinical situations that is fostered by personal reflection and reflection with others). RPQ scoring was done along 6-point response scale of $1=$ not at all, $2=$ slightly, $3=$ somewhat, $4=$ moderately, $5=$ very much, and $6=$ extremely. 7 The scores of each item was summed to produce a maximum of 96 total marks, and 16 was the least possible score. Each sub-domain had four questions with a total score of 24 . A higher score indicated a higher level of reflective practices among the postgraduate residents.

On-line survey questions included demographic information regarding gender, specialty and the year of training for back- ground information of the participants. A brief definition of reflective practices was provided in the questionnaire. Link of online questionnaire was shared with participants through internet in hospital whatsapp groups of postgraduate residents. Participation in the survey was voluntary. All respondents were informed that they were free to continue or quit and the submission of the questionnaire would be regarded as consent to participate. This was an anonymous survey as postgraduate residents were not asked to disclose theirnames.

The information collected was analysed by using statistical software SPSS-24. Qualitative variables were presented by calculating frequency and percentages. Mean and SD was calculated for the scores of questionnaires. These scores were compared among the postgraduate residents of paediatric medicine, paediatric surgery, and paediatric diagnostics. Independent ttest was used to measure the difference between mean scores among both groups and the difference on the basis of gender. A value of $p<0.05$ was considered as statistical significant.

\section{RESULTS}

Out of 175 study participants, 144 (82.3\%) were paediatric medicine residents followed by paediatric surgery $18(10.3 \%)$, and $13(7.4 \%)$ were from paediatric diagnostic. There were $84(48 \%)$ men and 91 (52\%) women in various years of residency training; 17 $(9.7 \%)$ in year-1, $31(17.7 \%)$ in year-2 and year-3, $58(33.1 \%)$ in year-4, and $38(21.7 \%)$ registrars. The percentages of responses of study participants to each question is given in Table I.

The overall mean score of the questionnaire was $69.97 \pm 10.79$ ( $95 \% \mathrm{Cl}: 68.36 \pm 71.58)$, out of 96 total score. The highest score was of critical appraisal $18.52 \pm 3.16$ (95\% Cl: $18.04 \pm 18.99)$. Mean score of each domain of RPQ is shown in Table ll. There was no difference of mean score of different domains based on gender, specialty oryear of training.

\section{DISCUSSION}

Healthcare providers have to respond to a range of complicated and poorly described circumstances. Experts practitioners have a tendency to make fast decisions that are applicable to these difficult situations; and they are able to construct a set of conceptual templates through a process of reflection-on action, which furtherly can be used effectively to handle the similar situation through reflection-in-action. ${ }^{3}$ Reflective practice has been adopted in many developed countries, however, it is still in an evolutionary process with little awareness in developing countries, like Pakistan. Reflection and reflective practice among educators and researchers in Pakistan will help them in more systematic and conceptual understanding of the teaching curriculum and process of education. ${ }^{8}$

The present authors used the RPQ, which had four sub-components of reflection; reflection-in-action, reflection-on-action, reflection with others and critical appraisal. ${ }^{5}$ In this study, postgraduate residents had the lowest score of reflection-in-action $16.82 \pm 3.90$ out of 24 as compared to other subcomponents like critical-appraisal (18.52 \pm 3.16$)$. 
Table I: Responses of study participants.

\begin{tabular}{|c|c|c|c|c|c|c|c|}
\hline \multirow[b]{2}{*}{$\begin{array}{l}\text { Q. } \\
\text { No }\end{array}$} & \multirow[t]{2}{*}{ Questions } & \multicolumn{6}{|c|}{ Response scores } \\
\hline & & Extremely & Very much & Moderately & Some what & Slightly & Not at all \\
\hline 1 & $\begin{array}{l}\text { After interacting with patients I think about how things went } \\
\text { during the interaction }\end{array}$ & $15(8.6 \%)$ & $52(29.7 \%)$ & $8(50.3 \%)$ & $15(8.6 \%)$ & $3(1.7 \%)$ & $2(1.1 \%)$ \\
\hline 2 & $\begin{array}{l}\text { When reflecting with others about my work I develop new } \\
\text { perspectives }\end{array}$ & $8(4.6 \%)$ & $69(39.4 \%)$ & $64(36.6 \%)$ & $27(15.4 \%)$ & $3(1.7 \%)$ & $4(2.3 \%)$ \\
\hline 3 & $\begin{array}{l}\text { I gain new insights when reflecting with others about my } \\
\text { work }\end{array}$ & $14(8.0 \%)$ & $82(46.9 \%)$ & $57(32.6 \%)$ & $12(6.9 \%)$ & $8(4.6 \%)$ & $2(1.1 \%)$ \\
\hline 4 & $\begin{array}{l}\text { After interacting with patients I wonder about the patient's } \\
\text { experience of the interaction }\end{array}$ & $16(9.1 \%)$ & $50(28.6 \%)$ & $71(40.6 \%)$ & $28(16.0 \%)$ & $6(3.4 \%)$ & $4(2.3 \%)$ \\
\hline 5 & $\begin{array}{l}\text { I find that reflecting with others about my work helps me to } \\
\text { work out problems I might be having }\end{array}$ & $19(10.9 \%)$ & $78(44.6 \%)$ & $52(29.7 \%)$ & $20(11.4 \%)$ & $2(1.1 \%)$ & $4(2.3 \%)$ \\
\hline 6 & $\begin{array}{l}\text { After interacting with patients I spend time thinking about } \\
\text { what was said and done }\end{array}$ & $13(7.4 \%)$ & $69(39.4 \%)$ & $54(30 / 9 \%)$ & $22(12.6 \%)$ & $12(6.9 \%)$ & $5(2.9 \%)$ \\
\hline 7 & I think about my weaknesses for working with patients & $45(25.7 \%)$ & $59(33.7 \%)$ & $39(22.3 \%)$ & $23(13.1 \%)$ & $7(4.0 \%)$ & $2(1.1 \%)$ \\
\hline 8 & $\begin{array}{l}\text { After interacting with patients I wonder about my own } \\
\text { experience of the interaction }\end{array}$ & $21(12.0 \%)$ & $59(33.7 \%)$ & $60(34.3 \%)$ & $28(16 \%)$ & $3(1.7 \%)$ & $4(2.3 \%)$ \\
\hline 9 & $\begin{array}{l}\text { During interactions with patients I consider how their } \\
\text { personal thoughts and feelings are influencing the } \\
\text { interaction }\end{array}$ & $22(12.6 \%)$ & $64(36.6 \%)$ & $50(28.6 \%)$ & $31(17.7 \%)$ & $3(1.7 \%)$ & $5(2.9 \%)$ \\
\hline 10 & $\begin{array}{l}\text { I think about how I might improve my ability to work with } \\
\text { patients }\end{array}$ & $33(18.9 \%)$ & $99(56.6 \%)$ & $30(17.1 \%)$ & $9(5.1 \%)$ & $3(1.7 \%)$ & $1(0.6 \%)$ \\
\hline 11 & $\begin{array}{l}\text { During interactions with patients I consider how my personal } \\
\text { thoughts and feelings are influencing the interaction }\end{array}$ & $20(11.4 \%)$ & $64(36.4 \%)$ & $50(28.6 \%)$ & $24(13.7 \%)$ & $8(4.6 \%)$ & $9(5.1 \%)$ \\
\hline 12 & $\begin{array}{l}\text { I critically evaluate the strategies and techniques I use in my } \\
\text { work with patients }\end{array}$ & $19(10.9 \%)$ & $72(41.1 \%)$ & $59(33.7 \%)$ & $18(10.3 \%)$ & $3(1.7 \%)$ & $4(2.3 \%)$ \\
\hline 13 & I think about my strengths for working with patients & $27(15.4 \%)$ & $90(51.4 \%)$ & $37(21.1 \%)$ & $15(8.6 \%)$ & $3(1.7 \%)$ & $3(1.7 \%)$ \\
\hline 14 & $\begin{array}{l}\text { When reflecting with others about my work I become aware } \\
\text { of things I had not previously considered }\end{array}$ & $20(11.4 \%)$ & $82(46.9 \%)$ & $49(28.0 \%)$ & $19(10.9 \%)$ & $3(1.7 \%)$ & $2(1.1 \%)$ \\
\hline 15 & $\begin{array}{l}\text { During interactions with patients I recognize when my pre- } \\
\text { existing beliefs are influencing the interaction }\end{array}$ & $15(8.6 \%)$ & $39(22.3 \%)$ & $72(41.1 \%)$ & $30(17.1 \%)$ & $8(4.6 \%)$ & $11(6.3 \%)$ \\
\hline 16 & $\begin{array}{l}\text { During interactions with patients I recognize when my } \\
\text { patient's pre-existing beliefs are influencing the interaction }\end{array}$ & $29(16.6 \%)$ & $58(33.1 \%)$ & $53(30.3 \%)$ & $23(13.1 \%)$ & $4(2.3 \%)$ & $8(4.6 \%)$ \\
\hline
\end{tabular}

Table II: Combined mean score of four-item sub-components.

Table II: Combined mean score of four-item sub-components.
\begin{tabular}{|l|c|c|c|}
\hline Reflection domains & Maximum score & $\begin{array}{c}\text { Cumulative score } \\
\text { Mean } \pm \text { SD }\end{array}$ & 95\% Confidence interval \\
\hline Reflection in action & 24 & $16.82 \pm 3.90$ & $16.23 \pm 17.40$ \\
\hline Reflection on action & 24 & $16.99 \pm 3.01$ & $16.54 \pm 17.44$ \\
\hline Reflection with others & 24 & $17.64 \pm 2.99$ & $17.19 \pm 18.08$ \\
\hline Critical appraisal & 24 & $18.52 \pm 3.16$ & $18.04 \pm 18.99$ \\
\hline Overall RPQ Score & 96 & $69.97 \pm 10.79$ & $68.36 \pm 71.58$ \\
\hline
\end{tabular}

Sobral's findings revealed that between the beginning and the end of training, the majority of students improved their reflection-in-learning scores. Students with high reflection-in-learning scores had higher grade-point scores and greater self-reported diagnostic ability in the following semester than those with low scores. ${ }^{9}$ Sagasser, in a qualitative research, interpreted about learning from patient encounters as a complex process in which residents rely on information gathered during patient encounter and actively assess after gathering information whether or not to consult their supervisors. Most notably, after the clinical encounter, the residents checked different sources of information such as web-based information, medical books or available guidelines to ensure that their decisions were right. Supervisor have a major role in this learning process as they impart knowledge by discussion, reassurance, providing feedback and finally assessing trainees' knowledge and skills. ${ }^{10}$

In this study, questions on reflections on evaluating the strategies and techniques I use in my work with patients and improving the ability to work with patients, were highly scored. A research by Miller found a strong positive associa- tion between students' reflective ability and global communication skill scores. The ability to adapt knowledge to patients' needs and address feelings was linked to reflective ability and writing. ${ }^{11}$

About $85 \%$ postgraduate residents were moderately to strongly agreed to reflecting with others about the work, helping to workout problems. Jennifer's research showed that when students have a tough time in the clinical environment, they reflect on how difficult clinical situations have impacted their wellbeing. Undergraduate students shared these events with their peers more than the postgraduate residents, according to this report. Moreover the students who discussed the events with their peers had higher resilience. ${ }^{12}$ Eighty percent of the study participants agreed that after interacting with patients, they wonder about my own experience of the interaction. In healthcare profession, reflective practice is extremely important. Technical and professional experience is in high demand due to the ever changing context and development of medical knowledge. Reflective practice will help to develop a sense of autonomy and self-direction in one's learning process. Reflective prac- 
tice and checklist can help medical practitioners and students to minimise diagnostic errors in patient care. ${ }^{13}$

Feedback from others act as a focus by which individuals develop meaning about themselves. Reflected appraisals are a form of feedback that can be congruent or incongruent with a person's self-perception. Instead, they associate with and seek feedback from people who confirm their own self-perceptions. ${ }^{14}$ Hulsman found that introducing critical self-reflection to physicians at a young age helps them accept an essential ability for continued life-long learning and become mindful health care professionals. ${ }^{15} \mathrm{~A}$ research by Levin showed that the three highest scored domains regarding reflection were consequences of actions; having insight by recognizing conflict; and using critical analysis for meaning making. Moreover faculty feedback was successful in moving students toward more critical reflection. ${ }^{16}$ The reflective capacity brings a change for many and was seen as long-term and possibly permanent by most. ${ }^{17}$

Sobral's research revealed how reflection affects academic achievement in subtle ways. As compared to their peers, high achievers had higher reflection scores at the start and end of the term. ${ }^{18}$ Reflection-in-action, reflection-on-action and critical-appraisal score were all above the moderate range in our study. Morgan et al. found that there are multiple opportunities for reflection, including trainee self-reflection and facilitated reflection with the trainer, all of which lead to the development of critical lifelong learning skills. ${ }^{19}$

Literature showed that "It takes a whole doctor to treat a whole patient. In the case of a narrative-based practice of empathetic witnessing, it also takes a whole (embodied) doctor to hear a whole patient. Such "wholeness" must involve a self-aware practice that incorporates both professional and personal realities. The personal narrative exercise is one mean toward recognising, acknowledging, and incorporating the physician's self-story into their clinical practice." 20,21

Evidence suggests that reflection-in-learning is linked to preparation for self-regulation of learning and can be useful in improving diagnostic abilities. ${ }^{9}$ Measuring reflection-in-learning may be a valuable method in evaluating the learning profiles of medical students.

Being a single-centred survey and including only Paediatric residents and registrars is the biggest limitation of the study making it difficult to generalize to postgraduate trainees working in other specialties. Multi-centre studies are needed to analyse the reflective practices of the doctors in their postgraduate training and moreover we are planning for a similar study on the undergraduate students to find out the differences of reflective practices between undergraduate and postgraduate training.

\section{CONCLUSION}

The overall reflective practices of paediatric postgraduate residents are good irrespective of specialty, gender or year of training. Critical appraisal of interaction in the reflection is the highest scored domain. The reflective practice questionnaire can be used for evaluation of postgraduate medical education initiatives and to identify postgraduate residents who might need targeted interventions for their future career.

\section{ETHICAL APPROVAL:}

Ethical approval was obtained from Institution Review Board, CHICH (No.2021-254-CHICH, dated: 18.03-2021).

\section{CONFLICT OF INTEREST:}

The authors declared no conflict of interest.

\section{AUTHORS' CONTRIBUTION:}

$A B$ : Conceived, data analysis and manuscript writing.

II: Data collection.

HU: Data management.

AA: Proofreading.

IN: Drafting.

NS: Critical review.

\section{REFERENCES}

1. Ring M, Majd I, Mehta DH. Keeping integrative medicine continuing medical education on the cutting edge - and compliant. J Altern Complement Med 2020; 26(3):166-71. doi: 10.1089/acm.2020.0037.

2. Ng SL, Kinsella EA, Friesen F, Hodges B. Reclaiming a theoretical orientation to reflection in medical education research: A critical narrative review. Med Educ 2015; 49(5):461-75. doi: 10.1111/medu.12680.

3. Sandars J. The use of reflection in medical education: AMEE guide No. 44. Med Teach 2009; 31(8):685-95. doi: 10.1080/01421590903050374.

4. Hargreaves K. Reflection in medical education. J Univ Teach Learn Pract 2016; 13(2):1-19.

5. Rogers SL, Priddis LE, Michels N, Tieman M, Van Winkle LJ. Applications of the reflective practice questionnaire in medical education. BMC Med Educ 2019; 19(1):1-11. doi: 10.1186/s12909-019-1481-6.

6. Azim S, Shamim M. Educational theories that inform the educational strategies for teaching ethics in undergraduate medical education. J Pak Med Assoc 2020; 70(1):123-8. doi: 10.5455/JPMA.487.

7. Priddis L, Rogers SL. Development of the reflective practice questionnaire: Preliminary findings. Reflective Pract Routledge 2018; 19(1):89-104.

8. Akhtar MI. Integration of reflective practice in postgraduate medical education. J Coll Physicians Surg Pak 2018; 28(10):812-3.

9. Sobral DT. An appraisal of medical students' reflection-in-action. Med Edu 2000; 34(3):182-7.

10. Sagasser MH, Kramer AWM. Self-entrustment: How trainees' self-regulated learning supports participation in the workplace. Adv Heal Sci Educ 2017; 22(4):931-49. doi: 


\subsection{7/s10459-016-9723-4}

11. Miller OK, Micheal K, BrandGothelf A, Palombo M. The associations between reflective ability and communication skills among medical students. Patient Educ Couns 2021; 104(1):92-8. doi: 10.1016/j.pec.2020.06.028.

12. Houpy JC, Lee WW, Woodruff JN, Pincavage AT, Houpy JC, Lee WW, et al. Medical student resilience and stressful clinical events during clinical training Medical student resilience and stressful clinical events during clinical training. Med Educ Online 2017; 22(01):1-8. doi: 10.1080/10872981. 2017.1320187.

13. Jorwekar GJ. An appraisal of medical students' reflection-in. Int J Res Med Sci 2017; 5(4):1188.

14. Goldie J. The formation of professional identity in medical students: Considerations for educators. Med Teach 2012; 34(9):e641-e8. doi: 10.3109/0142159X.2012.687476.

15. Hulsman RL, Harmsen AB, Fabriek M. Reflective teaching of medical communication. Patient Educ Couns 2009; 74(2):142-9. doi: 10.1016/j.pec.2008.10.009.

16. Scott R, Levin, Cai F, Noronha N. Diseases, Doctors, and Divas: Cultivating reflective capacity in preclinical medical students through a critical examination of opera. J Learn through Arts Title 2017; 13(1):1-13. doi.org/10.21977/ D913128321

17. Paget T. Reflective practice and clinical outcomes: Practi-tioners' views on how reflective practice has influenced their clinical practice. J Clin Nurs 2001; 10(2):204-14. doi: 10.1046/j.1365-2702.2001.00482.x.

18. Sobral DT. Medical students' reflection in learning in relation to approaches to study and academic achievement. Med Teach 2001; 23(5):508-13. doi: 10.1080/01421590 120042973.

19. Morgan S, Henderson K, Tapley A, Scott J, Driel M Van, Thomson A, et al. How we use patient encounter data for reflective learning in family medicine training How we use patient encounter data for reflective learning in family medicine training. Med Teach 2015; 37(10):897-900. doi: 10.3109/0142159X.2014.970626.

20. Donley C. Changing images of healers. Lit Med 1991; 10:18-33. doi: 10.1353/lm.2011.0090.

21. Dasgupta S, Charon R. Personal illness narratives: Using reflective writing to teach empathy. Acad Med 2004; 19(4):351-6. 